\title{
Educação a distância no discurso publicitário: o imaginário discursivo sobre o aluno
}

\author{
Isabel Cristiane Jerônimo \\ Universidade Estadual de Londrina (UEL), Londrina, Paraná, Brasil \\ cristianejeronimo@uel.br \\ Eliana Maria Severino Donaio Ruiz \\ Universidade Estadual de Londrina (UEL), Londrina, Paraná, Brasil \\ elianaruiz@uel.br
}

DOI: http://dx.doi.org/10.21165/el.v46i3.1803

\begin{abstract}
Resumo
O crescimento efetivo de cursos de graduação e pós-graduação na modalidade a distância no território nacional torna compreensível o empenho que os responsáveis pelo marketing de instituições de ensino superior despendem em maneiras de seduzir o público-alvo a optar pelos cursos que oferece, considerando-se o enorme leque de possibilidades existentes. Partindo desse pressuposto, temos por objetivo, neste artigo, investigar de que forma é construído o imaginário discursivo a respeito do estudante universitário em propagandas de cursos de educação a distância, veiculadas em páginas de abertura de sites de instituições particulares. O enfoque teórico para essa investigação é o da Análise de Discurso de orientação francesa, com algumas contribuições da Gramática do Design Visual de Kress e Van Leeuwen (1996).
\end{abstract}

Palavras-chave: imaginário discursivo; aluno a distância; publicidade.

\section{Educación a la distancia en el discurso publicitario: el imaginario discursivo acerca} del alumno

\section{Resumen}

Con el crecimiento efectivo de los cursos de graduación y posgrado en la modalidad de enseñanza digital realizado a la distancia en el territorio nacional, es comprensible que los responsables por la promoción y divulgación de los Centros de Enseñanza Superior busquen maneras de atraer su público-objetivo, a la vez que lo convenza a elegir sus cursos ofrecidos, teniendo en cuenta la amplia gama de posibilidades ofrecidas. Partiendo de esa presuposición, nuestro objetivo en esta investigación es intentar comprender de qué manera es construido el imaginario discursivo sobre el estudiante universitario en la publicidad de los cursos de educación a la distancia transmitidos en las primeras páginas de los sitios de instituciones privadas. El enfoque teórico de esta investigación es basado en el análisis del discurso de orientación francesa, con algunas contribuciones de la Gramática do Design Visual, de Kress e Van Leeuwen (1996).

Palabras-clave: imaginario discursivo; alumno a distancia; publicidad.

\section{Introdução}

Quando se pensa em educação em nível superior, o binômio ensinar-aprender sempre esteve vinculado a instituições de ensino fisicamente delimitadas e estabilizadas no tempo e no espaço. O conhecimento legitimado circulava exclusivamente dentro de 
instituições físicas, para as quais os indivíduos se deslocavam com o intuito de adquirir conhecimento e, assim, firmar-se no mercado de trabalho.

Desde o século XIX e, principalmente, no início do XXI, surge outra possibilidade além do ensino tradicional em nível de graduação e pós-graduação: a Educação a Distância (EaD), nos moldes que a conhecemos hoje. As primeiras experiências registradas em $\mathrm{EaD}$ em nosso país datam do século $\mathrm{XX}$, sempre vinculadas à formação profissional. Nas décadas de 1970 e 1980, cursos supletivos a distância eram oferecidos por instituições não governamentais, por meio de aulas via satélite, complementadas por materiais impressos.

Porém, em função da emergência e desenvolvimento das tecnologias digitais de informação e comunicação (TDIC), não são mais os alunos que se deslocam físicamente em busca de espaços de conhecimento, mas, sim, são esses espaços que estão, virtualmente, à disposição dos que se interessam em acessá-los via internet. O local em que se dá esse acesso já não é mais fator limitador para os que, por meio do Ensino a Distância (EaD), querem fazer parte do rol de universitários. ${ }^{1}$

O uso das TDIC na EaD foi incorporado pelas instituições de ensino superior (IES) somente a partir da década de 1990, razão pela qual Belloni (2002, p. 123) entende a $\mathrm{EaD}$ como "parte de um processo de inovação educacional mais amplo que é a integração das novas tecnologias de informação e comunicação nos processos educacionais". Já conforme Moran (2002, p. 1), "Educação a Distância é o processo de ensino-aprendizagem, mediado por tecnologias, onde professores e alunos estão separados espacial e/ou temporalmente", podendo haver ou não encontros presenciais. Para o autor, essa modalidade é mais adequada a adultos, principalmente aos que possuem experiência em estudo individual e pesquisa, como ocorre na graduação e na pósgraduação, característica que leva Moore e Kearsley (2007, p. 197) a postularem que os responsáveis por elaborar os programas dos cursos a distância precisam levar em conta as motivações do adulto que escolhe essa modalidade, já que se trata de alguém com muitas preocupações em relação ao trabalho, à família e à vida social.

A sociedade capitalista contemporânea exige do sujeito que opta pela $\mathrm{EaD}$ a capacidade de lidar com realidades mais complexas com competência e rapidez, ou seja, ser "um trabalhador multiqualificado e multicompetente, capaz de gerir situações de grupo, de se adaptar a situações novas, sempre pronto a aprender. Em suma, um trabalhador mais informado e mais autônomo", pontua Belloni (2009, p. 39), para quem a noção de autonomia é fundamental nesse tipo de aprendizado, sendo compreendida como a ação de um sujeito ativo que realiza sua própria aprendizagem. Ainda segundo a autora, habilidades essenciais a um aluno dessa modalidade são autodisciplina, automotivação, responsabilidade e capacidade de gerenciar o seu tempo. Pré-disposição individual para aprender a aprender também é fundamental em tempos de ensino mediado por computador, na medida em que há um isolamento físico maior do aluno em relação aos colegas e professores, comparativamente ao ensino presencial. Há outros componentes importantes que constituem o processo como professores, tutores e

\footnotetext{
${ }^{1}$ Neste trabalho usaremos a sigla EaD para Ensino a Distância e Educação a Distância. Moran (2002) prefere Educação a Distância a Ensino a Distância, por ser uma expressão mais abrangente e não colocar em foco somente o papel do professor. Entretanto, julga as duas expressões como não plenamente adequadas.
} 
responsáveis pela elaboração do material pedagógico, mas, as características postuladas para o aprendiz dessa modalidade, evidentemente, influenciam o modo como a EaD é conduzida nas IES, uma vez que os cursos por elas oferecidos seguem a tendência do mercado. Dessa forma, compreende-se a razão pela qual, no quadro do capitalismo, "a educação a distância aparece como um novo filão do mercado educacional, que tende a ser extremamente promissor do ponto de vista econômico" (BELLONI, 2002, p. 134).

Uma primeira aproximação entre os potenciais alunos-consumidores e as IES que oferecem cursos na modalidade a distância pode se dar por meio de propaganda habilmente veiculada em páginas de abertura de sites de instituições particulares, como pudemos observar numa rápida pesquisa, na internet. Nosso interesse em explorar o tema se justifica por se tratar de instituições que criam estratégias de marketing para atrair seus alunos, diferentemente das instituições públicas que, embora também marquem presença em sites da internet, não as apresentam. Nosso foco, portanto, está circunscrito à relação entre o universo da $\mathrm{EaD}$ e o discurso publicitário, que constrói uma identidade de aluno por meio de representações. As discussões sobre identidade e representação deste artigo embasam-se nas contribuições dos Estudos Culturais.

$\mathrm{Na}$ medida em que a relação $\mathrm{EaD}$ vs. publicidade insere-se num contexto social denominado por Bauman (2008) de modernidade líquida, uma sociedade na qual as relações humanas baseiam-se no imediatismo, na mudança constante, na rapidez, além de ser conhecida como a "sociedade do conhecimento", que traz consigo o discurso da eficiência, do empreendedorismo e da competitividade, propomos uma reflexão acerca de como o mercado educacional elabora seu discurso, aqui concretizado em textos publicitários digitais, para representar esse aluno contemporâneo que se utiliza de mecanismos virtuais visando conseguir legitimação acadêmica. Assim, sob o aporte teórico da Análise de Discurso de orientação francesa, pretendemos refletir sobre a forma com que a publicidade engendra essa realidade na construção de seu discurso, por meio da projeção de uma imagem de aluno a distância em propagandas veiculadas em sites de instituições de ensino superior. Que imagem é essa e que efeitos de sentido se pretende produzir ao construí-la? De que maneira se constitui esse discurso sobre/para o aluno universitário a distância? Quais são as dimensões sócio-históricas envolvidas nesse acontecimento discursivo? Como se articula a materialidade do discurso publicitário à memória discursiva dos leitores de sites de cursos superiores a distância? Essas são as questões que norteiam este trabalho.

\section{Notas sobre o discurso publicitário}

A proliferação da propaganda dos cursos virtuais de graduação e pós-graduação veiculados na internet é um fenômeno recente que se constitui num contexto social complexo, formado por várias vozes. Entender de que forma as mudanças sócio-históricas articulam-se às escolhas linguísticas do enunciador de peças publicitárias, construindo representações do aluno a distância, possibilita a compreensão de como esse dizer se constitui e por que tem espaço na sociedade contemporânea.

O discurso publicitário, segundo Soulages (1996, p. 142), pode ser visto como "um processo de produção plena de formas culturais e se afirma no espaço cultural como um dos suportes mais visíveis das representações de identidades". Trata-se, pois, de "um dizer que remexe os imaginários socioculturais, criando efeitos de sentido, instaurando identidades [...] [impondo] valores, mitos, ideais e outras elaborações simbólicas" 
(CARVALHO, 1996, p. 13). Assim, as representações criadas pela publicidade, como também por outras esferas de comunicação humana, são formas de ver e de valorar o mundo, já que, como afirma Hall (1997 apud WOODWARD, 2014, p. 8), "a representação atua para classificar o mundo e nossas relações com o seu interior” [...]. É por meio dos significados produzidos pelas representações que damos sentido à nossa experiência e àquilo que somos", posicionando-nos como sujeitos.

A construção dos significados ocorre por meio dos chamados saberes, os quais, segundo Charaudeau (2013), dividem-se em saberes de conhecimento e saberes de crença. Os primeiros referem-se aos conhecimentos comprovados cientificamente e, portanto, validados por um discurso de autoridade; já os saberes de crença baseiam-se na subjetividade humana, nos julgamentos que são feitos pelos indivíduos em relação aos fatos. Muitas vezes, na tentativa de manipular o outro, verdades de crença podem ser vendidas como verdades de conhecimento, na forma de imaginários discursivos:

À medida que esses saberes, enquanto representações sociais, constroem o real como universo de significação, falaremos de imaginários [...]. Considerando que circulam no interior de um grupo social, instituindo-se em normas de referência por seus membros, falaremos de "imaginários sociodiscursivos". (CHARAUDEAU, 2013, p. 203).

Ainda de acordo com o autor, o imaginário social é um universo de significações que constitui as identidades e não pode ser visto como totalmente consciente ${ }^{2}$. Para Charaudeau (2013, p. 207), "Os imaginários sociodiscursivos circulam em um espaço de interdiscursividade. Dão testemunho das identidades coletivas, da percepção que os indivíduos e os grupos têm dos acontecimentos, dos julgamentos que fazem de suas atividades sociais.".

Para a materialização desse imaginário sociodiscursivo, o discurso publicitário, assim como outros discursos, utiliza-se de recursos argumentativos, estilísticos, léxicosemânticos, fonéticos e morfossintáticos, a fim de atingir seus propósitos. A competência textual-discursiva de quem opera esses recursos faz toda a diferença quando a tarefa é convencer o público-alvo:

Toda a estrutura publicitária sustenta uma argumentação icônico-linguística que leva o consumidor a convencer-se consciente ou inconscientemente. Tem a forma de diálogo, mas produz uma relação assimétrica, na qual o emissor, embora use o imperativo, transmite uma expressão alheia a si própria. $\mathrm{O}$ verdadeiro emissor permanece ausente do circuito da fala; o receptor, contudo, é atingido pela atenção desse emissor em relação ao objeto. (CARVALHO, 1996, p. 13).

Produzida sócio-historicamente numa conjuntura capitalista, a publicidade reflete características dessa sociedade e visa fixar determinadas identidades para nela atuarem. Uma das vozes mais ativas na sociedade de consumo busca gerar, numa espécie de simulacro, a ilusão da individualidade, ou seja, de que cada um de nós é um ser especial, único, singular, importante para o funcionamento do todo. A promessa de inserir o

\footnotetext{
${ }^{2}$ Instituições como escola e igreja podem até se valer de discursos em que se racionaliza um ou outro aspecto desses imaginários, mas outros são encontrados de maneira não consciente nos julgamentos implícitos, nos modos de se dizer e estão tão assimilados pela sociedade que são vistos de forma naturalizada. Outros imaginários formam o chamado inconsciente coletivo, identificável apenas por uma abordagem mais aprofundada.
} 
indivíduo na sociedade de consumo soa como uma possibilidade de dar-lhe poder e, por conseguinte, o prazer advindo da sensação de pertencimento a um grupo socialmente valorizado - deleite que durará até o próximo anúncio.

De acordo com Soulages (1996, p. 147), o ritual sociolinguageiro, ${ }^{3}$ ou seja, a base de construção do discurso publicitário, define-se a partir da escolha de três componentes: a mídia, o produto e o consumidor.

A natureza da mídia escolhida é de extrema importância: trata-se da seleção, pelo anunciante, de um suporte específico de visibilidade. No caso deste trabalho, é o computador conectado à internet e acessado por um potencial aluno-cliente, suscitando modos peculiares e novos de interlocução. Visto que a publicidade digital tem como característica principal a interatividade, ao contrário da propaganda tradicional, em que o produto "procura" o público, é o internauta que vai em busca do produto, utilizando-se do endereço eletrônico ou auxiliado por sites de busca, de modo que a publicidade digital caracteriza-se como sendo mais segmentada.

Além da mídia, lembra Soulages (1996), o anunciante deve optar por um modo de qualificação do produto. Em se tratando de cursos a distância, não temos a venda de um produto físico stricto sensu, mas a de um bem simbólico que, dependendo da construção discursiva, pode ser visto como um bem de consumo, na medida em que a valorização econômica (mercantilização) pode transformar um bem simbólico em mercadoria (THOMPSON, 2004).

Por fim, afirma Soulages (1996), o anunciante precisa definir, no interior da atividade linguageira, uma forma de instituir uma relação com o potencial consumidor, de modo a construir um parceiro. Na publicidade virtual, há uma desmassificação na comunicação, ou seja, os consumidores da mídia é que aparecem no controle e não quem enuncia, uma vez que "[...] diferente da linguagem das mídias de massa, ao invés do convencimento unilateral, a conquista deve ser realizada clique a clique, a fim de manter o usuário interessado no assunto" (LAPOLLI; GAUTHIER, 2008, p. 46). Assim, no caso dos anúncios publicitários de cursos a distância em páginas de sites de IES particulares, o enunciador levará em conta, na produção de seu discurso, não mais um público-alvo sem rosto, massificado, mas considerará as características e interesses próprios desse grupo desejoso de cursar uma graduação ou pós-graduação, gerando representações que possam caracterizá-lo e criar identificações, de forma a garantir que o potencial aluno de EAD ingresse na instituição de ensino que vende sua marca. Compreender a forma como o enunciador manipula aspectos linguísticos e discursivos para a construção das representações que identificam esse aluno universitário de cursos a distância na contemporaneidade é o objetivo do presente estudo.

\section{O imaginário discursivo sobre o aluno de educação a distância}

O material proposto para a análise compõe-se de 17 anúncios publicitários veiculados em páginas de abertura de sites de cursos a distância de IES particulares que oferecem cursos de graduação e pós-graduação. A opção por se pesquisar esses textos em suporte online se deu por ser a internet a forma atualmente mais utilizada pelos

\footnotetext{
${ }^{3}$ Ritual sociolinguageiro é uma expressão empregada por Charaudeau (1982).
} 
anunciantes (SOULAGES, 1996) e pelos consumidores que procuram essa modalidade de ensino, pela agilidade na busca de informações, principalmente quando o indivíduo quer comparar preços e serviços.

Em relação ao período pesquisado, nove das propagandas selecionadas datam do mês de dezembro de 2014 e oito são dos meses de março e abril de 2015. A coleta se deu por meio do site de buscas Google, utilizando-se EaD como palavra-chave. A partir daí, seguimos a ordem de pesquisa oferecida pelo próprio site, acessando as ocorrências de IES particulares que ofereciam cursos a distância. Dado que os modos de significação desse discurso são multissemióticos, do grande número de propagandas encontradas, foram selecionadas as peças publicitárias que apresentam potencial discursivo relevante para a análise, ou seja, textos que veiculam significativa linguagem verbal e não verbal relativamente à construção do imaginário que investigamos. As regularidades discursivas que cooperam na construção das representações contemporâneas acerca do potencial aluno universitário a distância apresentam-se por meio de dizeres, que ora relacionam $\mathrm{EaD}$ a sucesso profissional, ou frisam o aspecto econômico dos cursos atrelando-o à imagem do sujeito consumidor; ora utilizam testemunho autorizado ${ }^{4}$ para validar $o$ discurso educacional, ou apresentam vantagens de se cursar a modalidade a distância; ora valorizam o sujeito consumidor por meio da promessa de inclusão. Tais regularidades serão interpretadas à luz do contexto sócio-histórico-ideológico contemporâneo, diálogo que possibilitará compreender como se dá a construção dos sentidos nas referidas peças.

Cabem, inicialmente, algumas observações acerca das condições de produção dos textos do corpus. Econômica e culturalmente, a sociedade brasileira atual, assim como tantas outras que adotam o capitalismo como modo de produção, caracteriza-se como uma sociedade de consumo, na qual, "a publicidade aliada à estratégia da obsolescência programada $^{5}$ e às formas de crédito ao consumidor são, atualmente, as principais estratégias da sociedade de consumo que acabam por manter os consumidores na condição de fantoches do consumismo" (PADILHA; BONIFÁCIO, 2013, [n.p.]). Tratase, portanto, de uma sociedade comandada pela lógica do lucro, na qual a publicidade comparece como engrenagem fundamental, direcionando nossas escolhas e estimulando nossos desejos por meio de representações várias.

Além do aspecto econômico, a publicidade é uma forma de controle social. Por meio dela, o enunciador é capaz de suscitar desejos no enunciatário, direcionando-o para que se perceba necessitado daquilo que está sendo anunciado, já que também quer estar incluído socialmente e ser participante dos valores veiculados pela propaganda. Assim, o sujeito da sociedade capitalista é assediado pelo desejo de consumo em diversas áreas, até mesmo naquela em que o objeto não é algo material, mas um bem simbólico, como é o caso do conhecimento, valorizado por essa sociedade, já que, por meio dele, o sujeito poderá ter um emprego melhor e ganhar mais dinheiro, fazendo a economia girar. Denominado por Bourdieu (1989) de capital cultural, esse tipo de conhecimento é constituído pelos inúmeros saberes que o sujeito acumula no decorrer de sua vida, relacionando-se tanto à gama de conhecimentos transmitidos para o indivíduo

\footnotetext{
${ }^{4}$ De acordo com Garcia (1992), o testemunho autorizado ocorre quando o pesquisador utiliza afirmações alheias dignas de crédito, aplicando o que se chama de métodos de autoridade.

${ }^{5}$ A obsolescência programada é um dos efeitos nefastos trazidos pelo excesso do consumo, uma vez que "[...] reflete o incentivo planejado para o rápido descarte dos produtos comprados, para que o ciclo produção-consumo-produção seja acelerado ao seu máximo" (PADILHA; BONIFÁCIO, 2013, [n.p.]).
} 
intergeracionalmente (capital incorporado), quanto ao aspecto institucionalizado do saber, que diz respeito aos títulos, diplomas e outras credenciais educacionais. Ainda segundo o autor, numa sociedade de classes, o capital cultural muitas vezes pode ser utilizado como instrumento de dominação e poder, já que os portadores de um maior capital cultural valorizado pela sociedade hegemônica terão maior distinção e oportunidades.

$\mathrm{Na}$ contemporaneidade, essa distinção adquirida socialmente por meio do conhecimento passa a ser acessível, também, em função das facilidades tecnológicas que passaram a ser agregadas aos contextos educacionais. Uma vez incorporadas ao ensino, as TDIC surgem como forma de atender aos que não têm possibilidade de comparecer física e diariamente a uma instituição educacional, para poder se graduar ou pós-graduar. E a sociedade capitalista cobra cada vez mais capacitação do indivíduo, forçando-o a buscar formação sempre, a fim de ser considerado um profissional qualificado.

Assim, é possível destacar, como uma das regularidades do corpus, dizeres que aliam aquisição de conhecimento a êxito profissional imediato. As instituições de EaD visam, de modo não transparente, convencer o potencial aluno, geralmente proveniente de classes menos privilegiadas, da possibilidade de também ascender social e economicamente por meio da acumulação de capital cultural institucionalizado. Por isso há, com frequência, na construção desse discurso, a seleção do vocábulo sucesso ${ }^{6}$. Embora se trate de palavra com significado subjetivo, no contexto acadêmico significa vencer etapas e conseguir o diploma, a credencial educacional. É possível perceber isso nos seguintes dizeres:

MBA EaD UNOESTE. Transforme sua carreira em referência de sucesso. ${ }^{7}$

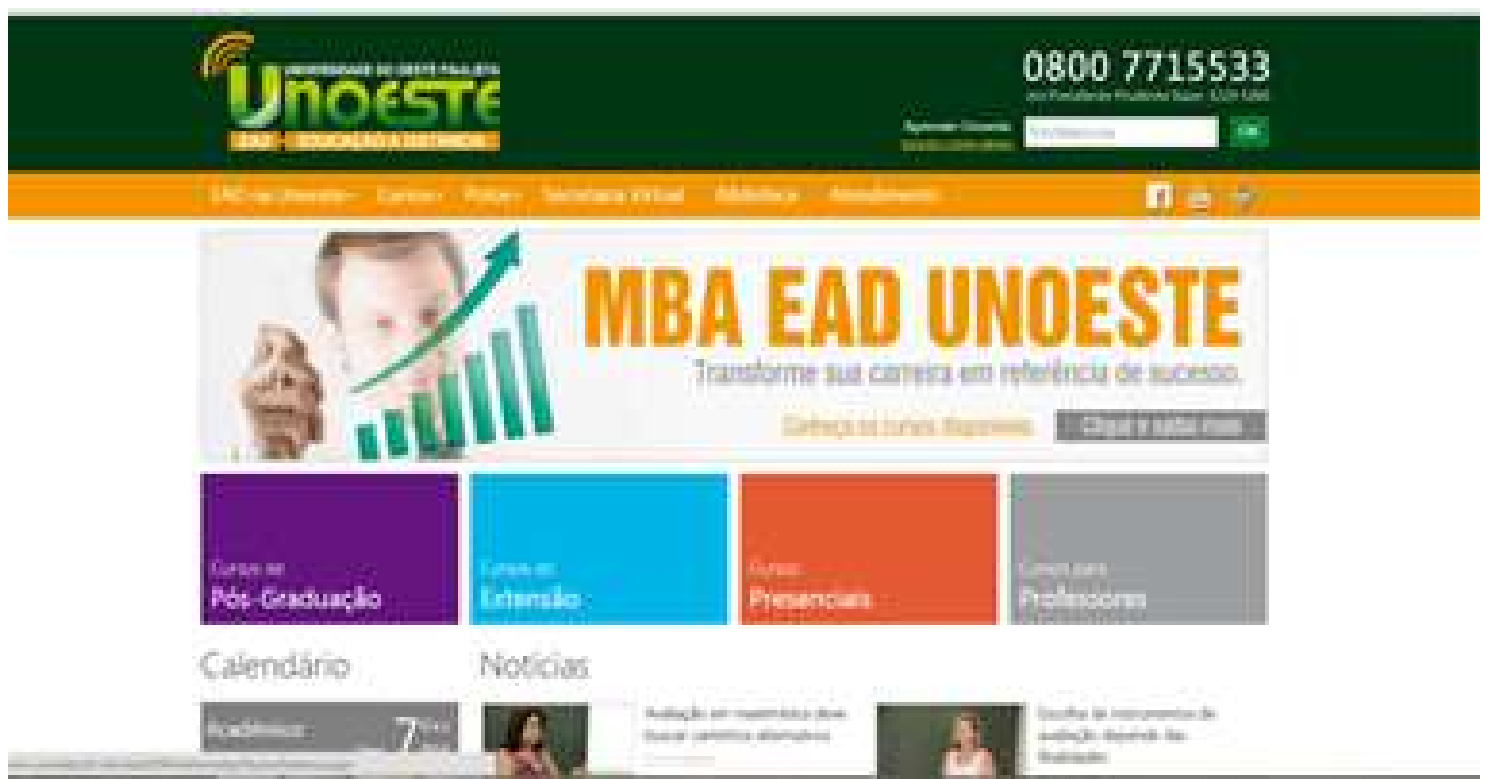

\footnotetext{
${ }^{6}$ No dicionário Houaiss (2004), uma das acepções da palavra sucesso é "o que alcança êxito ou fama".

${ }^{7}$ Disponível em: <http://www.unoeste.br/site/ead/_imagens/EADSite-Banners_2.jpg>. Acesso em: 07 dez. 2014.
} 
Constrói-se, assim, uma relação de causa e efeito entre EaD e sucesso profissional. Em outras palavras, a urgência do mundo moderno, a rapidez com que as coisas devem acontecer fazem-se presentes na suposta relação estabelecida pelo enunciador entre curso a distância e imediato sucesso na profissão, ideias engendradas em íntima relação. E tal relação emerge ainda mais forte e convincente nesses dizeres, na medida em que aqueles que se interessam por essa modalidade, conforme já apontado (BELLONI, 2009), são, em princípio, pessoas mais experientes, preocupadas com trabalho, família e vida social, portanto, têm mais pressa de alcançar o sucesso.

Ainda enfocando a ideia de sucesso, os subentendidos são acionados pelas relações entre texto e imagem, na peça publicitária em questão (recorte discursivo 01). É possível afirmar, em conformidade com os preceitos da Gramática do Design Visual de Kress e Van Leeuwen (1996), que a imagem apresenta uma estrutura narrativa com apenas um participante interativo ${ }^{9}$ (um dos personagens que participam da ação encenada), representado, no caso, por um homem observando um gráfico que demonstra evolução ascendente de dados - o que, no plano da expressão, é dado na forma de um vetor. Como há, na narrativa apresentada, apenas um personagem em cena, trata-se de um "processo de ação não transacional" ". Numa perspectiva representacional, levando-se em conta os contextos educacional e profissional em que a propaganda se insere, o homem pode ser identificado como um membro do mercado de trabalho que analisa o currículo (representado pelo gráfico) de um aluno a distância e percebe seu êxito, concretizado, no plano da expressão, por um vetor em elevação. A imagem é construída a fim de gerar um efeito de sentido em que se prevê um futuro instantâneo de sucesso para o aluno que cursar a modalidade a distância na universidade em questão. E o diálogo verbo-imagético se dá com o enunciado de slogan "Transforme sua carreira em referência de sucesso", posicionado logo abaixo do nome do curso (MBA EAD UNOESTE).

Como os discursos não são homogêneos, outra voz, aliada à ideia de êxito profissional, tem lugar nessas peças publicitárias para discursivizar a imagem de aluno a distância: a que trata do fator financeiro. Em uma sociedade de classes, a educação e os títulos valorizados não estão disponíveis para todos. Dessa forma, o enunciador apresenta a instituição de ensino em tela como vinculada à expansão de oportunidades educacionais, por vender o saber a preços acessíveis - estratégia recorrente nas peças analisadas. Assim, cria-se uma imagem de aluno a distância como um sujeito que, não tendo provindo das classes mais abastadas da sociedade, pode, entretanto, pagar pela aquisição do conhecimento com esforço pessoal:

Para inscrições até 31 de dezembro, 30\% de desconto na primeira mensalidade. Imperdível: estude em 2015 com preços de 2014. ${ }^{11}$

\footnotetext{
${ }^{8}$ Disponível em: <.http://www.vestibulares.br/locales/global/img/banners/BannerOfertaOpcao03.jpg>. Acesso em: 13 mar. 2015.

${ }^{9}$ Termos como interativo e interação poderão, vez ou outra, ser mantidos, por conta da filiação teórica dos autores revisitados.

${ }^{10}$ Em processos narrativos transacionais, segundo os autores, tem-se a presença de dois ou mais personagens interagindo e a presença ou não de um vetor (KRESS; VAN LEEUWEN, 1996).

${ }^{11}$ Disponível em: <http://www.ead.cesumar.br/site/upload/banners/42/banner_42.jpg>. Acesso em: 07 dez. 2014.
} 
A partir de $R \$ 119,00$ mensais. ${ }^{12}$

(05) UNIGRAN Matrículas abertas e totalmente gratuitas. $50 \%$ de desconto na primeira parcela. Investimento Mensal: $R \$ 201,00 .{ }^{13}$

(06) Estácio. Graduação a distância. A partir de $\mathbf{R} \$ \mathbf{1 2 0 , 0 0}$ por mês. ${ }^{14}$

O uso da locução a partir de (recortes 04, 05 e 06), que indica "ponto de partida, um limite inicial, a começar de", traz a ideia de início e continuidade, gerando o sentido de que os preços praticados com descontos, em suaves prestações mensais, são um convite ao ingresso no mundo acadêmico pelos interessados, mas os esforços dos alunos/consumidores terão que ser redobrados em termos financeiros, conforme progredirem no curso (PADILHA; BONIFÁCIO, 2013, [n.p.]). Essas vantagens econômicas do parcelamento também são expressas pelo uso de numerais ordinais que indicam sucessão: na primeira mensalidade (03) e na primeira parcela (05). Em nível lexical, o uso do adjetivo imperdivel (03), que significa "aquilo que deve ser aproveitado, que não se pode desperdiçar”, cria o sentido de que se trata de oportunidade única para os sujeitos que não provêm da elite e que deixá-la passar é não só um desperdício de ganhos futuros garantidos, mas, também, a manutenção de um distanciamento do poder social. O modalizador totalmente, em Matrículas abertas e totalmente gratuitas (05), potencializa a ideia de gratuidade da matrícula, já presente no adjetivo gratuitas.

Outro aspecto a ser analisado nos dizeres são os verbos: transforme (em 01, acima: Transforme sua carreira em referência de sucesso), Faça e especialize-se (07), conquiste e inscreva-se (08), garanta (09), estude (10), nos recortes abaixo:

(07) Faça a diferença no ambiente educacional. Especialize-se de maneira rápida, agora também em 7 meses. ${ }^{15}$

(08) Uniasselvi. Chegou a sua vez. Conquiste o seu diploma. Inscreva-se já! ${ }^{16}$

(09) Garanta seu lugar na Unopar. Ensino a Distância \# é pra você. ${ }^{17}$

(10) Imperdivel: estude em 2015 com preços de 2014. ${ }^{18}$

Todas as formas verbais apontadas suscitam ação por parte do sujeito, pois possuem traços semânticos de atividade. O emprego do modo imperativo, como é de praxe, na propaganda, em geral, serve para incitar o enunciatário, no caso, convidando-o a agir e a mudar de vida por meio do conhecimento. Fica pressuposto, portanto, que, para exercer o papel social de aluno a distância o indivíduo não pode ser passivo, temeroso de riscos, mas precisa ser alguém que agarre a oportunidade que lhe está sendo oferecida, num efeito de sentido de que o poder da mudança está em suas mãos, não havendo outra coisa a fazer a não ser tomar essa atitude empreendedora - tão valorizada na sociedade

\footnotetext{
${ }^{12}$ Disponível em: <https://ead.uninassau.edu.br/inicio>. Acesso em: 19 ago. 2014.

${ }^{13}$ Disponível em: <http://www.vestibularunigran.com.br/>. Acesso em: 13 mai. 2014.

14 Disponível em: <http://cursos.estacio.br/?estado=SP\&gclid=CN6jy7bfwcUCFQMWHwodi2QA5g\#>. Acesso em: 14 mai. 2015.

${ }^{15}$ Disponível em: <http://www.unoeste.br/site/ead/_imagens/EADSite-Banners_2.jpg>. Acesso em: 07 dez. 2014.

${ }^{16}$ Disponível em: <http://www.nead.com.br/>. Acesso em: 07 dez. 2014.

${ }^{17}$ Disponível em: <https://vestibular.unoparead.com.br/inscricao/index>. Acesso em: 15 abr. 2015.

${ }^{18}$ Disponível em: <http://www.ead.cesumar.br/site/upload/banners/42/banner_42.jpg >. Acesso em: 07 dez. 2014.
} 
atual, por relacionar ação inovadora do sujeito com criação de oportunidades pessoais. Com o emprego do imperativo, então, o enunciador procura persuadir o potencial aluno a fazer o que lhe interessa. Nas palavras de Charaudeau (2010), como quem enuncia na propaganda não ocupa uma posição hierárquica superior em relação ao enunciatário e, por isso, não precisa empregar meios para coagi-lo, utiliza-se ideologicamente da palavra e criam-se estratégias para fazer o sujeito crer que será o beneficiário de seu próprio ato, tomando a atitude que o enunciador pretendia que tomasse desde o momento em que planejou seu texto.

Nessa dispersão de vozes nas propagandas, outro fator contundente para se criar uma imagem de aluno a distância que consiga fazer com que o enunciatário se identifique com ela é a inserção, pelo enunciador, da voz que legitima cursos superiores e especializações no país: o Ministério da Educação e Cultura (MEC):

(11) Faculdade São Luis. Pós-graduação EaD. Para o conhecimento não há distância. Credenciado pelo $\mathrm{MEC} .^{19}$

(12) Unicesumar \#semdistância do conhecimento. Autorizado e reconhecido pelo MEC. Educação superior a distância. ${ }^{20}$

\section{Estácio. Graduação a distância. Mesma qualidade e cursos certificados pelo MEC. ${ }^{21}$}

Em busca do lucro, proliferam faculdades e universidades de baixa qualidade de ensino, e como a EaD ainda é vista com reservas por certos setores da sociedade, quando comparada ao ensino presencial, certificação é um ponto importante a ser destacado, a fim de convencer o público-alvo a aderir a essa modalidade de ensino. Isso justifica a seleção das formas nominais credenciado (11), autorizado e reconhecido (12), e certificados (13) nesses dizeres, muito embora as sutis diferenças de sentido entre elas possa não ser partilhada pelo enunciatário. Ainda assim, inserir tal testemunho autorizado nessa formação discursiva - aliado ao fato de que nem todas as instituições possuem esse trunfo de poder usá-lo em seus anúncios - pode fazer com que a credibilidade em relação às que o utilizam em seus anúncios seja um fator decisivo para a escolha pelo sujeito. Busca-se, portanto, criar uma imagem de aluno a distância responsável, preocupado tanto com a aquisição do conhecimento, quanto com a certificação do curso pela instituição da qual fará parte.

Outro ponto importante a se mencionar acerca do discurso nessas peças publicitárias é a enumeração das supostas vantagens do "produto" anunciado: a mercadoria EaD (THOMPSON, 2004). Nos dizeres, observa-se que essas vantagens estão relacionadas aos seguintes aspectos: tempo, paridade com o ensino presencial $\mathrm{e}$ comodidade. Iniciemos pelo tempo:

\footnotetext{
19 Disponível em: <http://saoluis.br/ead/wp-content/uploads/2011/08/banner.png>. Acesso em: 07 dez. 2014.

${ }^{20}$ Disponível em: <http://www.ead.cesumar.br/site/upload/banners/42/banner_42.jpg>. Acesso em: 07 dez. 2014.

${ }^{21}$ Disponível em: <http://cursos.estacio.br/?estado=SP\&gclid=CN6jy7bfwcUCFQMWHwodi2. $>$. Acesso em: 14 mai. 2015.
} 
(14) Faça a diferença no ambiente educacional. Especialize-se de maneira rápida, agora também em 7 meses. ${ }^{22}$

\section{FACEL. Desenvolvendo talentos, Formando profissionais. EaD Pós-graduação em 8 meses. ${ }^{23}$}

O tempo reduzido dos cursos de pós-graduação apresentado por esses dois anúncios é uma das vantagens apresentadas para quem pretende cursar a modalidade a distância. Conforme apontado, o aluno a distância caracteriza-se por ser uma pessoa mais experiente e a ele pode interessar fazer um curso de pós-graduação que dure menos tempo que cursos presenciais, já que o mercado lhe cobra formação contínua. Daí o tempo ser expresso, nesses dizeres, em algarismos e meses - 7 meses (14), 8 meses (15) - a fim de destacar a rapidez do processo.

A similaridade com os cursos presenciais é outra suposta vantagem regularmente encontrada pelas peças publicitárias analisadas:

(16) Faça Anhembi Morumbi on line. Os mesmos professores, a mesma aula, o mesmo diploma. ${ }^{24}$

(17) Estácio. Graduação a distância. Mesma qualidade e cursos certificados pelo MEC. Estude e quando quiser. ${ }^{25}$

É significativa a ênfase criada pela reiteração do adjetivo mesmo - mesmos professores, mesma aula, mesmo diploma (16), mesma qualidade (17) - que pretende fixar na mente do aluno em potencial que este não terá prejuízo algum se fizer a opção por essa modalidade de ensino, já que há uma suposta garantia de identidade (entre o presencial e o a distância) com relação aos elementos fundamentais do processo, como professores, aula, material didático e diploma, gerando qualidade equivalente.

Como mais uma vantagem de se cursar a modalidade a distância, apresenta-se também nos dizeres a ideia de comodidade:

(18) Graduação a distância Unissau \#eutambémposso. Você estuda onde, quando e como quiser. Suas aulas são todas oferecidas pela internet com o suporte de um tutor a distância. Você só irá ao polo no final do módulo para a realização das provas. ${ }^{26}$

(19) Educação a distância. 8 novos cursos. Inscrições abertas. EaD UNIFEV. Com a UNIFEV ON LINE qualquer hora é hora de estudar. ${ }^{27}$

UNIGRAN Net. Faculdade via internet. Faça onde estiver. Pós-graduação a distância. ${ }^{28}$

\footnotetext{
${ }^{22}$ Disponível em: <http://www.unoeste.br/site/ead/_imagens/EADSite-Banners_2.jpg>. Acesso em: 07 dez. 2014.

${ }^{23}$ Disponível em: <http://facel.com.br./posead/index.php\#area>. Acesso em: 14 mai. 2015.

${ }^{24}$ Disponível em: $<$ http://portal.anhembi.br/estude-aqui/educacao-a-distancia/cursos/>. Acesso em: $07 \mathrm{dez}$. 2014.

25 "Estude e quando quiser": texto conforme o original. Disponível em:

$<$ http://cursos.estacio.br/?estado=SP\&gclid=CN6jy7bfwcUCFQMWHwodi2Q. $>$. Acesso em: 14 mai. 2015.

${ }^{26}$ Disponível em: <https://ead.uninassau.edu.br/inicio>. Acesso em: 19 ago. 2015.

27 Disponível em: <http://www.unifevonline.com.br/site/imagens/logo_ead.png>. Acesso em: 13 mai. 2015.

${ }^{28}$ Disponível em: <http://www.vestibularunigran.com.br/>. Acesso em: 13 mai. 2015.
} 
A suposta comodidade apresentada pelo enunciador relaciona-se tanto ao plano físico, quanto cognitivo. O uso do advérbio só, no recorte (18) (Você só irá ao polo no final do módulo), produz com ênfase o efeito de sentido de que a conhecida locomoção diária e cansativa do sujeito, no plano físico, para chegar às instituições delimitadas no espaço geográfico dos cursos presenciais está descartada. Portanto, o potencial aluno economizaria tempo e dinheiro frequentando poucas vezes os polos do curso a distância.

Quanto à comodidade relacionada ao plano cognitivo, a construção discursiva pode ser observada pela escolha das locuções que remetem às condições de espaço, tempo e modo: Você estuda onde, quando e como quiser (18), qualquer hora é hora de estudar (19), Faça onde estiver (20). Empregando-as, o enunciador desvincula o estudo a distância da ideia de compromisso, aliando ao desejo do sujeito as ideias de liberdade quanto às escolhas de espaço, tempo e modo para estudar - respectivamente materializadas no plano linguístico pelo pronome onde e pelos advérbios quando e como, reforçados pelo pronome qualquer. Busca-se, com isso, produzir uma imagem de aluno que pode atuar de forma autônoma, independente e livre, sem precisar se prender a imposições de local, horário e forma de estudo, típicas dos cursos presenciais.

Como as peças publicitárias trabalham com a ideia das vantagens da $\mathrm{EaD}$, as dificuldades, obviamente, são silenciadas. A imagem a seguir ilustra esse fato:

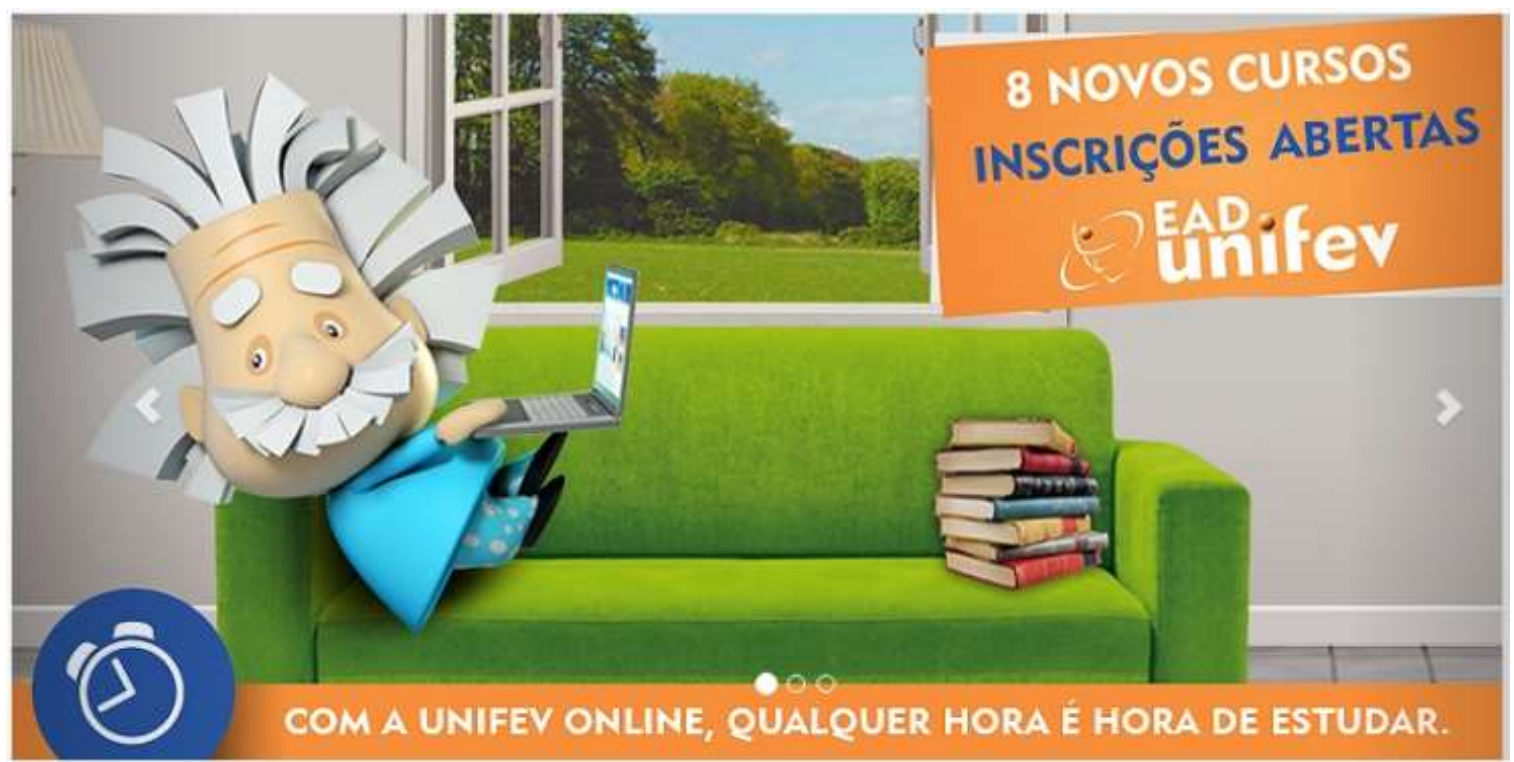

(21) Com a UNIFEV ON LINE qualquer hora é hora de estudar. ${ }^{29}$

Do ponto de vista dos significados ideacionais (fonte para a construção de conteúdo e do campo da ação social, conforme KRESS; VAN LEEUWEN, 1996), o texto traz a figura de um pequeno Einstein, o sujeito (participante interativo, no dizer dos autores) num processo de ação não transacional, acomodado em um sofá, com um notebook no colo, e diante de alguns livros empilhados no lado oposto do assento. Na cena, o geniozinho simboliza o potencial aluno universitário a distância que, confortavelmente, no aconchego do lar (representado pela janela aberta para um jardim e pelo abajur no canto esquerdo), interage tranquilamente com a IES a distância,

${ }^{29}$ Disponível em: <http://www.unifevonline.com.br/site/>. Acesso em: 13 mai. 2015. 
representada pelo computador. Entretanto, seu olhar (na figura do recorte discursivo 21) sequer está voltado para a tela; o participante mira de frente o enunciatário, o potencial aluno a distância, procurando cumplicidade (SOULAGES, 1996). Tudo se passa como se, para ele, fosse "só alegria", como se não houvesse nenhum problema, nenhum fator complicador para o andamento do processo de ensino-aprendizagem a distância. No aconchego do lar, tem-se a liberdade de estudar no momento em que se desejar - sentido imagético em diálogo estreito com o enunciado verbal Com a UNIFEV ON LINE qualquer hora é hora de estudar. Os livros, ao longe, que poderiam acionar, na memória discursiva do enunciatário, a ideia de trabalho árduo em busca do conhecimento, passam ao largo, pois representam, no plano da expressão, uma possibilidade eventual e remota de pesquisa, uma vez que figuram em segundo plano na imagem, relativamente ao aparelho em mãos - este, sim, apresentado como verdadeiro portal para um conhecimento sem limites. De modo que, na cena, o participante aluno a distância comparece numa condição de paz, comodidade, calmaria, produzindo efeitos de sentido de que estudar na EaD é sinônimo de bem-estar, de felicidade, de prazer.

Por fim, observa-se no corpus uma recorrência de enunciados assertivos que projetam o enunciatário para dentro do universo do conhecimento, num suposto movimento de inclusão social:

(22) Graduação a distância Unissau. \#eutambémposso. ${ }^{30}$

(23) Uniasselvi. Chegou a sua vez. ${ }^{31}$

(24) Cruzeiro do Sul virtual. Você não tem limites, nem a sala de aula. ${ }^{32}$

(25) Graduação a Distância CNEC: você de estudante a gestor da própria carreira. ${ }^{33}$

As afirmações \#eutambémposso (22), Chegou a sua vez (23), Você não tem limites (24) e você de estudante a gestor da própria carreira (25) servem ao propósito de carregar o enunciatário para o centro da cena, seja pelo uso da primeira ou da segunda pessoa do discurso, criando dizeres que fazem com que o potencial sujeito consumidor aluno sintase valorizado, único, capaz, incluído socialmente por meio dessa nova possibilidade que é o ensino a distância.

Temos, em (22), o emprego da primeira pessoa (\#eutambémposso), que dá voz ao aluno em potencial, fazendo-o afirmar-se como incluído na sociedade por meio do advérbio também, que indica comparação e se inscreve como condição de equivalência ou similitude. Assim, o enunciatário "eu" excluído da sociedade do conhecimento também fala como se estivesse na posição-sujeito de incluído no sistema de possibilidades econômico-educacionais. E de acordo com a hipótese de que essa inclusão seja de cunho social/financeiro, emerge o sentido de que a $\mathrm{EaD}$ vem para incluir aquele sem condições econômicas, valorizando-o. O verbo modal (posso) selecionado para compor o enunciado

\footnotetext{
${ }^{30}$ Disponível em: <https://ead.uninassau.edu.br/inicio>. Acesso em: 19 ago. 2015.

${ }^{31}$ Disponível em: <http://www.nead.com.br/>. Acesso em: 07 dez. 2014.

$32 \quad$ Disponível

em:

$<$ http://www.cruzeirodosul.edu.br/wpcontent/uploads/2014/10/ead_semipresencial_site_pag.jpg $>$. Acesso em: 13 mar. 2015.

33 Disponível em: <http://cnec22px.rtrk.com.br/ead/graduacao/wpcontent/uploads/2014/09/banner_jpg>. Acesso em: 07 dez. 2014.
} 
cria um sentido de possibilidade, de capacidade atribuída a esse enunciatário de acreditar que cursos superiores e especializações podem fazer parte de sua história, fazendo com que o aluno/consumidor creia em seu potencial para mudar de vida e alcançar o sucesso na sociedade de classes. E por estar inserido numa hashtag ${ }^{34}$, o enunciado \#eutambémposso ganha atualização e dinamicidade, sugerindo a ideia de reiteração a cada visualização do site da IES (LAPOLLI; GAUTHIER, 2008).

Já nos dizeres (23), (24) e (25), ainda em conformidade com a imagem de aluno a distância como alguém que não teve oportunidades acadêmicas na vida e precisa de um estímulo para desenvolver seu potencial, o enunciador usa outra estratégia discursiva, introduzindo afirmações acerca do enunciatário, através dos pronomes de segunda pessoa você e sua: Você não tem limites; Chegou a sua vez; você, de estudante a gestor da própria carreira. A imagem de aluno a distância é apresentada, pois, de forma positiva, pelo emprego de asserções que induzem à ideia de certeza, de verdade acerca das inúmeras possibilidades oferecidas pela $\mathrm{EaD}$.

O sentido de que o conhecimento abre portas e resgata o aluno a distância do anonimato social, fazendo dele alguém que tem espaço e atuação no mundo do capital, emerge exemplarmente na peça (26) a seguir.

$(26)^{35}$

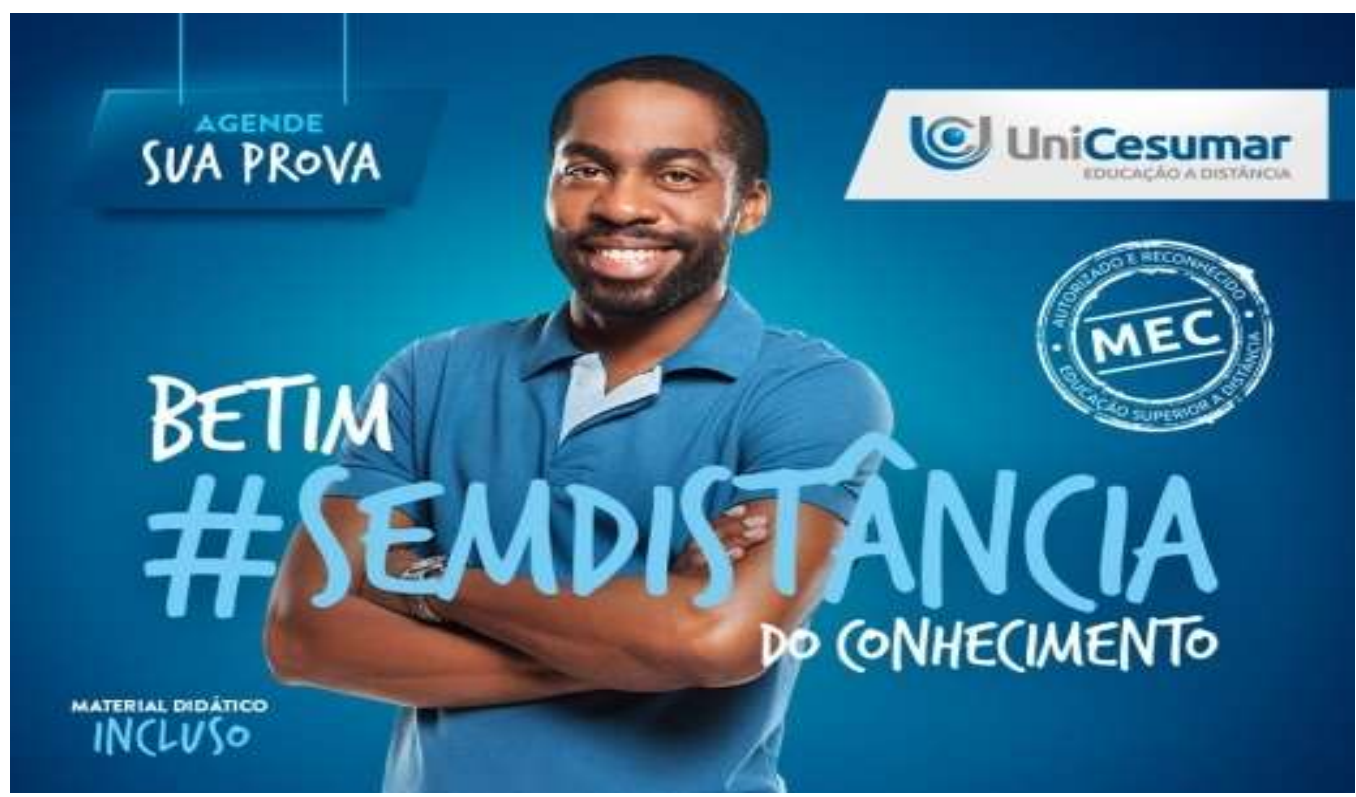

Segundo Kress e Van Leeuwen (1996), a imagem desse anúncio traz, no tocante aos significados ideacionais, uma representação conceitual que descreve o participante em foco - o aluno a distância - em termos de classe.

\footnotetext{
34 “Tags são palavras-chave (relevantes) ou termos associados a uma informação, tópico ou discussão que se deseja indexar de forma explícita no aplicativo Twitter, e também adicionado ao Facebook, Google+ e/ou Instagram. Hashtags são compostas pela palavra-chave do assunto antecedida pelo símbolo cerquilha (\#). As hashtags viram hiperlinks dentro da rede, indexáveis pelos mecanismos de busca.". Disponível em: $<$ https://pt.wikipedia.org/wiki/Hashtag>. Acesso em 17 dez. 2016. 35

$<$ https://www.ead.cesumar.br/site/inscreva_se/?utm_source=ead\&utm_medium=site\&utm_campaign=ba nner-home-desconto-30-porcento>. Acesso em: 07 dez. 2014.
} 
Com relação aos significados interpessoais, temos o conhecido ator global Lázaro Ramos posando de frente para o enunciatário, num plano médio de enquadramento (até a região do quadril). Por estar sorrindo e fitando-o no mesmo nível de seus olhos, trava com este uma relação de demanda, solicitando proximidade e criando uma relação de afinidade. Já a postura de braços cruzados, no plano da expressão, pode estar tanto reforçando o sentido de tranquilidade, como denotando poder por parte do participante representado, numa demonstração de afirmação da personalidade.

Ao ator é atribuído, metaforicamente, o simbolismo da credibilidade em relação à instituição anunciada: Lázaro Ramos é um artista de inegável sucesso na atualidade. A par disso, a escolha de um ator negro para essa peça publicitária tem a função precípua de estabelecer uma comparação: assim como ele, que foi capaz de conquistar uma carreira bem sucedida, conseguindo superar as adversidades - decorrentes do preconceito que ainda sobrevive, embora maquiado, num país como o Brasil, onde a escravidão foi uma das que mais perduraram ao longo da história -, o enunciatário pode, igualmente, vencer, por meio da aquisição do conhecimento proporcionado pelo $\mathrm{EaD}$ da instituição propagada. Parafrasticamente, é possível dizer: "assim como Lázaro Ramos é um vencedor em sua área, você também pode vencer, se optar pelo ensino a distância".

O diálogo da imagem com a parte verbal do anúncio ocorre por meio de três enunciados, estrategicamente posicionados na peça.

O enunciado de maior destaque é o que se encontra alocado no centro: \#SEMDISTANNCIADOCONHECIMENTO. Grafado em letras maiúsculas, que cooperam no estabelecimento da ênfase desejada, e formatado como uma hashtag, numa configuração típica de enunciados que circulam em gêneros discursivos digitais da atualidade, o enunciado é claramente dirigido aos jovens. Da expressão sem distância emerge o sentido de que, embora a modalidade de ensino seja a distância, se o potencial aluno optar por ela, não estará distante do saber, ao contrário, estará próximo dele, porque incluído na sociedade do conhecimento.

Um segundo enunciado que dialoga com a imagem é agende sua prova. É clara a referência à comodidade oferecida ao enunciatário, pela possibilidade de este agendar $a$ prova. E que prova seria? O emprego do artigo definido $a$ indica que a referência faz parte de um conhecimento partilhado que habita a memória discursiva de todos nós: o de que o ingresso a uma universidade no Brasil depende de o candidato ser aprovado num exame de admissão, o vestibular. Parafraseando: "você pode fazer seu exame vestibular no dia e hora que preferir". E com o imperativo agende, agrega-se, ainda, um outro efeito de sentido, o das vantagens que podem ser experimentadas pelo potencial aluno em virtude da inversão dos papéis hierárquicos tradicionalmente associados aos sujeitos da educação ("aqui nesta escola quem manda é você, o aluno, não mais o professor").

E o terceiro enunciado, ao qual se dá, em relação aos demais, menor destaque no diálogo verbo-imagético, pelo uso de uma fonte em tamanho reduzido e do seu posicionamento no canto inferior esquerdo da peça, é material didático INCLUSO, onde a palavra incluso aparece em caixa alta, gerando tanto o efeito de sentido de que não serão necessários maiores gastos além das mensalidades, como reforçando a ideia de inclusão já posta pela imagem do ator.

Há que se considerar, ainda, a emergência do mesmo sentido de cuidado com a certificação - mencionado quando da leitura dos recortes discursivos (11), (12) e (13) -, 
pelo recurso de simulação de um carimbo, do lado direito da peça, com os dizeres autorizado e reconhecido / MEC / educação superior a distância.

Enfim, irmanados pela mesma cor azul da camisa do ator e do fundo da peça, as palavras agende, \#sem distância e incluso são vestígios do entrecruzamento de sentidos que concorrem para o estabelecimento de um acirrado diálogo verbo-imagético. De maneira que o texto publicitário em tela é construído nesse poderoso batimento que range entre o verbal e o não verbal.

\section{Considerações finais}

Cairíamos em lugar comum se concluíssemos que a propaganda publicitária joga com cartas marcadas, quando produz certos efeitos de sentido entre os interlocutores.

Entretanto, vale dizer que, neste percurso de leitura, em que investigamos a projeção da imagem do estudante universitário a distância por anúncios publicitários veiculados em páginas de abertura de sites de instituições de ensino superior particulares, foi possível perceber como os dados analisados reforçam esse truísmo.

A análise empreendida nos levou a tecer alguns gestos interpretativos que nos permitem compreender como o marketing publicitário de cursos de graduação e pósgraduação a distância atua na construção de um promissor imaginário sociodiscursivo acerca de seu consumidor, o aluno em potencial. Nossa leitura revelou, em síntese, que o aluno que opta por cursos superiores a distância é representado discursivamente como um sujeito possuidor de um conjunto de atributos, meticulosamente planejados, que o caracterizam como sendo: um estudante que busca o sucesso profissional por meio de um curso credenciado que ofereça resultados rápidos; um sujeito com atitude, capaz de aproveitar as vantagens oferecidas pela $\mathrm{EaD}$ para mudar o rumo de sua história; e alguém que deixa a condição de excluído, para se apropriar, como consumidor, do capital cultural existente na sociedade por meio da EaD.

Trata-se, evidentemente, de um imaginário positivo acerca do sujeito consumidor, o estudante universitário, numa estratégia de sedução que visa não somente criar identificação deste potencial aluno a distância com o produto anunciado, os cursos na modalidade $\mathrm{EaD}$ ofertados por uma determinada instituição de ensino superior, mas habilmente fazê-lo crer, a si próprio, como uma mercadoria, tão passível de obsolescência quanto qualquer outro objeto de consumo na sociedade capitalista e industrializada do conhecimento.

\section{REFERÊNCIAS}

BAUMAN, Z. Vida para consumo: a transformação das pessoas em mercadoria. Rio de Janeiro: Zahar, 2008.

BELLONI, M. L. Ensaio sobre a educação a distância no Brasil. Educação \& Sociedade, ano XXIII, n. 78, p. 117-142, 2002.

. Educação a distância. 5. ed. Campinas: Autores associados, 2009.

BOURDIEU, P. O poder simbólico. Tradução de Fernando Tomaz. Rio de Janeiro: Bertrand Brasil, 1989. 
CARVAlHO, N. de. Publicidade: a linguagem da sedução. São Paulo: Ática, 1996.

CHARAUDEAU, P. Discurso político. 2. ed. São Paulo: Contexto, 2013.

O discurso propagandista: uma tipologia. In: MACHADO, I. L.; MELLO, R. $\overline{\text { Análises }}$ do Discurso hoje. Rio de Janeiro: Nova Fronteira (Lucerna), 2010. p. 57-78.

Eléments de semiolonguistique : d'une theorie du langage à une analyse du discours. In: Connexions, EPI, Paris, n. 38, p. 7-30, 1982.

GARCIA, O. M. Comunicação em prosa moderna. 15. ed. Rio de Janeiro: Editora da Fundação Getúlio Vargas, 1992.

HALL, S. Quem precisa da identidade. In: SILVA, T. T. da; HALL, S.; WOODWARD, K. (Org.). Identidade e diferença: a perspectiva dos Estudos Culturais. 6. ed. Petrópolis: Vozes, 2006. p. 103-133.

KRESS, G.; VAN LEEUWEN, T. Reading images: the grammar of the design visual. London: Routledge, 1996.

LAPOLLI, M.; GAUTHIER, F. Á. Publicidade na era digital: um desafio para hoje. Florianópolis: Pandion, 2008.

MOORE, M.; KEARSLEY, G. Educação a distância: uma visão integrada. Tradução de Roberto Galman. São Paulo: Cenage Learning, 2007.

MORAN, J. O que é educação a distância. p. 1-4. 2002. Disponível em: $<$ http://www2.eca.usp.br/moran/wp-content/uploads/2013/12/dist.pdf $>$. Acesso em: 15. ago. 2016.

PADILHA, V.; BONIFÁCIO, R. C. A. Obsolescência planejada: armadilha silenciosa na sociedade de consumo. 2013, [n.p]. Le Monde Diplomatique Brasil. Disponível em: $<$ http://www.diplomatique.org.br/artigo.php?id=1489>. Acesso em: 17 set. 2016.

SOULAGES, J.-C. Discurso e mensagens publicitárias. In: CARNEIRO, A. D. (Org.). $O$ discurso da mídia. Rio de Janeiro: Oficina do autor, 1996.

SUCESSO. In: HOUAISS, A.; VILLAR, M. de S. Mini Hoauiss: dicionário da língua portuguesa. 2. ed. Rio de Janeiro, 2004. p. 695.

THOMPSON, J. A mídia e a modernidade: uma teoria social da mídia. 6. ed. Petrópolis: Vozes, 2004.

TRINDADE, A. R. Distance Education for Europe. Lisboa: Universidade Aberta, 1992.

WOODWARD, K. Identidade e diferença: uma introdução teórica e conceitual. In: SILVA, T. T. da; HALL, S.; WOODWARD, K. (Org.). Identidade e diferença: a perspectiva dos Estudos Culturais. Petrópolis: Vozes, 2000. p. 7-72.

Recebido em: 20/02/2017

Aprovado em: 05/03/2017 